\title{
Uncertain infertility: three women's experiences
}

\section{Susan Quilliam}

\section{Background}

Any of us who have worked with women facing fertility problems know that the diagnosis is seldom instant or unequivocal. Typically, test follows test and it is only after months - or sometimes years - of exploration that it becomes clear that a woman will never conceive. Equally, with some conditions, until the woman tries to get pregnant, there is no way of testing for sure that those problems are irresolvable. Meanwhile she - along with her partner, friends and family - lives in a limbo of not knowing whether she will be a mother or not.

As with so many topics, when the Journal asked me to address this issue, the best way forward seemed to be to talk to the patients themselves. The three women whose experiences inform this article had very different stories to tell. Maria, at the age of 14 years, suspected that her congenital medical condition might make childbearing unwise and went to ask her GP's opinion, which was pessimistic. Jane (age 25 years) had been told that her amenorrhoea was down to being underweight, but doubtful, she insisted on full tests, which indicated polycystic ovary syndrome (PCOS). Kate, aged 36 years and eager to start a family, had been suffering from hot flushes, which proved to be perimenopausal. None of the women were told that they definitely could not have children; all of them were told that it might not be possible.

\section{First news}

Initially, all three responded with a surprising degree of positivity. Maria was almost too young to register the implications, so "I didn't ask about children, just moved straight on to asking whether I could have sex, which was a much bigger issue for me at the time!". Jane and Kate reported "being relieved to know the cause"; "it was quite nice to know what was happening with my body"; "once it was named, it was easier to deal with". In Kate's case, her consultant then gave her "exactly what I felt I needed", namely a wonderfully clear factual explanation of the likelihood that she was entering an early menopause. In Jane's case it was the radiographer performing her scan who informally diagnosed her condition; she turned up at her GP's surgery for the formal verdict knowing ahead of time what it would be.

So far, so good. And maybe it was this initial positivity that led to what happened next. Because all three women report that after the initial factual diagnosis, no further resources were offered, in terms either of information or emotional support. Jane in particular felt very negative: "I specifically booked an appointment with a woman because I thought I would get a more helpful response ... [I got] three very brief minutes - and not very helpful ones at that". None of the women were told what the possible options might be if they were infertile, none were guided through the treatment possibilities, none were given any space to express shock or distress.

\section{J Fam Plann Reprod Health Care 2008; 34(2): 123-124}

\section{Cambridge, UK}

Susan Quilliam, BA, Cert Ed, MNLP, Freelance Writer, Broadcaster and Agony Aunt

Correspondence to: Ms Susan Quilliam.

E-mail: susan@susanquilliam.com
I would add that these negativities are not a result of my somehow 'weighting' the sample to show our profession to worst advantage! These women's negative experiences only came to light during their interviews, and it is reflected in many chat room and message board accounts of receiving a diagnosis for infertility, PCOS and other linked conditions. What my three interviewees experienced is not the whole story; but it is not an atypical scenario.

\section{Practitioner motivation}

Let us, however, not be too hard on our own profession here. It seems to me entirely possible that the practitioners' motives, at least, were good. In the same way as oncologists rarely accompany a diagnosis with the words "and you're definitely going to die", these practitioners may well have been backing away from accompanying their diagnosis with the words "and you definitely can't have children". Given the very uncertainty of the situation, they may well have felt that heavy-duty information about infertility and its treatment was simply too early and too scare-mongering.

In addition, there seems to me to be an issue here about the emotional impact of the uncertain diagnosis on the practitioner as well as on the patient. We are trained to aim for - and hence, probably, to feel most comfortable with certainty. So we are arguably at our best when we have a clear sense of a medical condition, a clear remit of how to treat that condition, a clear sense that any treatment will be successful. Conversely, when all these factors are lacking, we may be at a loss how to react; we may feel just as helpless, and disempowered as our patients do. It may have been those feelings that led to Kate, Maria and Jane being so unsupported.

\section{Mourning the loss}

All three women, though coping in the short term, did ultimately need support. Jane handled things well for a week or so, even helping with her mother's own upset; then she burst into tears at work and had to take time off. Kate's marriage, already fragile, broke down because of her husband's unresponsive attitude to the diagnosis. Maria handled the news by burying it: "I don't think I told anyone not even my parents - just pushed it to the back of my mind".

\section{To consider oneself fully infertile - and to} claim from friends, partner and family the full support that demands - can feel self-indulgent and somehow deceifful.

Underpinning these reactions, of course, lay the classic emotional process of mourning a loss. Denial followed by grief, interspersed with fury and merging into bouts of depression, all aimed at eventual acceptance of loss, revival of hopes for the future, a rethinking of identity, a realigning of a life plan. Plus, as Kate realised: "I was [also] dealing with stuff from my childhood, and realising I couldn't be a mother, all in one lump". This is huge stuff, and for all three women it took time and emotional stamina to come to terms with the issues.

Or rather to come to terms with the possible issues. Because none of them knew for certain - Kate's was the most sure diagnosis but even her health professional said "there could be a miracle" - that the loss they were 
Box 1: When giving a diagnosis, even if that diagnosis is uncertain, the health professional should:

- Acknowledge to the patient that distressed feelings are natural and healthy.

- Offer information or sources of information about the condition.

- Encourage personal action and offer guidelines about what patients can do to help themselves.

- Check back on progress the next time the patient attends, even if for an unlinked reason.

Box 2: Useful resources for health professionals

- Infertility Network UK - support, information and advice. Tel: 08701 188083. www.infertilitynetworkuk.com

- The Daisy Network - support for women who have had a premature menopause. www.daisynetwork.org.uk

- Verity - support for women with PCOS www.verity-pcos.org.uk

- Endometriosis UK - support and information for women with endometriosis. Tel: 0808808 2227. www.endo.org.uk

- Fertility Friends - peer support for couples facing infertility problems. www.fertilityfriends.co.uk

mourning was real. Which raises an interesting issue, namely that while confirmed infertility is the worst of all worlds, unconfirmed infertility has an extra double bind within it. On the one hand, women can experience all the mourning that a confirmed diagnosis brings; on the other hand, to consider oneself fully infertile - and to claim from friends, partner and family the full support that demands can feel self-indulgent and somehow deceitful.

Add to that the feeling that one "should" stay positive, and that accepting the diagnosis as final means one is weak, and women can be blocked in their process of integrating what has happened. No one is suggesting that one should abandon hope, but uncertainty can leave a woman stranded in a no-man's land and feeling slightly guilty for that.

\section{What women need}

What could we health professionals have done here? What would these three women have wanted from their practitioners? (Box 1). None felt that they needed overwhelming support; all were realistic in their expectations and validating about practitioners in general. All felt that emotional rescue in particular was not down to the professionals. In Kate's words: "In some ways it felt like the emotional reactions were outside the health service - our responsibility rather than the health service's; we have more resources than they have".

\section{Offering even a few sentences of acknowledgment will mean the patient copes better, whatever the ultimate outcome.}

Nevertheless, all three women commented that they would have valued a simple acknowledgement of what a big issue all this was, and how normal and natural it was to feel devastated. As Maria said: "If you were diagnosed with cancer they would step up ... they would tell you that if you feel negative, you're not bad or mad". Instead, Maria was "told I was lucky to be alive at all", while Jane reported "the doctor basically just gave me the diagnosis and told me to go away until I wanted to have kids - then come back if it was worrying me".

All three women also wanted - and in Kate's case got clear and solid information (Box 2). Despite, perhaps because of, the uncertain prognosis, they wanted to know the facts; and they did not feel that knowing the worst case facts would have made them panic more, but instead feel more resourced.

These women also wanted validation for their own coping skills. Kate: "I knew I was responsible, and could get resources - but I don't think the doctor knew that". Jane: "I tried to take responsibility, turned up with information I'd got from the $B M J$. I needed a 'good for you'; what I got was a 'this won't work"'.

Finally, my interviewees needed continuity of care. The fact that coming to terms with possible infertility is an ongoing process made it crucial to be offered ongoing support, even on the lowest level of "do pop back". Plus, as all three women pointed out, future health problems of any kind that they developed might not only have been created by the original condition that led to the diagnosis, but might also have been created by the stress of the situation, and so practitioners would benefit from an awareness of past history. Despite this, none of the women were ever asked at a later time how they were coping with the diagnosis or whether they had reached a point of wanting to explore possible treatment options.

\section{Conclusions}

The end of each woman's story shows very different resolutions. A few years on, Kate has now gone through her menopause; she and her new husband have come to terms with childlessness and "I've got step-grandchildren, which is great, but I'm glad to give them back again". Maria, in a curious reversal of fortune, later found that she could have children, but "by that time, I was wedded to my career and my partner doesn't want children; I'm fine with that". Jane, whose story began only a year ago, has come some way along the road to resolution. She is still unsure whether she wants children but "while one pathway might be cut off to me it's not necessarily the end of the world".

The resolution for all these women, therefore, seems thus far positive. All have, in their own ways, worked through their grief process, and triumphed over their potential childlessness. So I am not in any way suggesting that their experiences have led to damage or tragedy; and I am fully aware that all over the country, health professionals are dealing with patients in ways that are many times more aware and supportive than these three women experienced.

But I do feel that there are lessons to be learned here with regard to uncertain diagnoses, whether they are of infertility or indeed any medical condition. We need to take on board that such a diagnosis may lead health professionals, often for the best of reasons, to believe that full-blown information and advice is not needed. That information and advice is needed and, where given (as in Kate's case), is extremely helpful. That postponing emotional support "because the worst hasn't happened" is shortsighted; offering even a few sentences of acknowledgment will mean the patient copes better, whatever the ultimate outcome. And that being aware of previous emotional flurries with regard to uncertain diagnoses will mean that we offer a more comprehensive and effective service the next time the patient turns up in the consulting room. Hard conclusions to hear perhaps but, I believe, necessary ones.

Statements on funding and competing interests

Funding None identified.

Competing interests None identified.

Author's note

Names have been changed to protect the interviewee's identities. 